\title{
The Revival of the Usage of Natural Fibers and Natural Dyes in Indonesian Textile
}

\author{
Dian Widiawati \\ Craft and Tradition Research Group, Faculty of fine Art and Design, \\ Bandung Institute of Technology
}

\begin{abstract}
Indonesia is known to possess abundant natural resources as well as a diverse textile tradition. Some examples of traditional textile materials are those made from indigenous natural fibers, such as silk, cotton, ramie, pineapple fibers, and banana frond fibers, which make use of natural dyes. The specific natural back ground and unique cultural tradition of a region strongly influence the creative process of local textile artisans and the visual form of textile works. After the invention of synthetic dyes, the usage of natural dyes has gradually decreased. However, the optimism in using traditional dyes recently emerges in the textile world in Indonesia. This tendency grows along with the issues of awareness of nature and the soaring popularity of back-to-nature lifestyle.

This study attempts to identify the relations between the usage of natural dyes in the past and its relevance to contemporary contexts. This study focuses on several topics, firstly the past role of natural dyes and the invention of synthetic dyes which outgrow natural dyes. Then, this study aims to explain why natural dyes are recently being reused in textile, which leads to identifying the contemporary position or role of natural dyes, besides the existence of synthetic dyes which technically possess various advantages. This study also aspires to identify the advantages and shortcomings of natural dyes based on the consumers' acceptance and certain contexts. The method used in this study is the qualitative descriptive method through interdisciplinary approaches.
\end{abstract}

Keywords: natural dyes; natural fibers; Indonesian traditional textile; textile.

\section{$1 \quad$ Introduction}

This paper comprises the preliminary research which discusses the revival of natural fibers and dyes in Indonesian textile. This paper also includes data of the usage of natural dyes in several regions in Indonesia and assumptions on the causes of revival, which requires further study.

Until the mid $-19^{\text {th }}$ century, when synthetic dyes came into use, all colors came from natural sources. How ever natural substances were used as body paint, cosmetics and coloring for pottery and baskets long before they were applied to textile fibers. Over 15,000 years ago our ancestor were using natural pigments to decorate the wall of cave painting of Altamira in Northern Spain and Lascaux in the south of France show. 
Many of these colors were of mineral rather than plant origin. They derived from deposits of iron, colored clay, malachite, and lapis lazuli. For example, and were often ground into pigment is easier to apply than a dye, because the finally ground color particles, which are held in suspension in a liquid, often with a thickener, are applied to the surface only. However, for a dye to be effective, the color particles must dissolve solution and must then be absorbed by the fiber molecules. The process is complicated by the fact that many dyes do not remain permanently fixed to the fiber without the used of some other substance to act as a bond mordant, from the Latin word mordere, meaning "bite" or "fasten". The most common mordant are metallic compounds of aluminum, iron, or copper.

In all probability, the earliest dyes were not fixed permanently to the fibers using a chemical mordant, and dyeing simply meant that the fibers were soaked or simmered in solutions from plants or other materials and became stained as a result.

\section{$2 \quad$ Using Natural Dyes in Indonesia}

Natural dyes for textiles have been used in Indonesia for quite a long time. These dyes are produced from wood or barks, leaves or roots of plants or trees from throughout the archipelago. Thus, from region to region, the colors obtained from these dyes are quite similar.

In the past, natural fibers and dyes were traditionally used as textile materials, which usage was emphasized on the fulfillment of spiritual purposes and the production of sacred traditional fabrics. It is unsurprising that the production process was usually time-consuming and highly complicated.

Traditional textiles, such as batik and weaving utilize various natural dyes taken from the surroundings of the producers, resulting in the invention of distinct regional colors, such as the characteristic red of the Lasem, batik taken from the mengkudu/noni roots (Morinda citrifolia). The characteristic dark blue from Tuban comes from the colouring process using the tarum/blue dye taken from indigo (Indigofera tinctoria). The yellowish brown to reddish brown color range, often found in batik from Yogya and Surakarta, comes from the soga plant (Peltophorum ferrugineium). The color range is also known as the sogan colors.

Natural colors in batik may be expressed in seemingly unlimited possibilities. The natural colors are formed through the dialectic of natural growth, a dynamic which is flexible, gentle, relaxed, naturally processed, and unhurried. This limitless can be described as a unique and ever-changing creation. 
The limitlessness of the possibilities may be seen as a unique and ever-changing creation. Two same mixtures of natural coloring matters using the same ingredients will not produce the exact same color.

The invention of synthetic dyes in 1856 in England by William Perkin, quickly replaced the usage of natural dyes. The red alizarin usually taken from the madder plant was replaced by a synthetic dye invented by Perkin and two German chemists; Graebe and Liebermann. The following years saw the development of synthetic indigo by Adolf von Baeyer (1904) to produce blue dyes [1].

The advent of synthetic dyes in Indonesia in the 1930s rendered the natural dyes obsolete. The process of batik production which had usually involved natural dyes, such as soga, indigo, and mengkudu roots, began to utilize synthetic dyes, such as naftol, indigosol, and rapid, direct, and reactive. In the following decades, textile producers using natural dyes were a rarity.

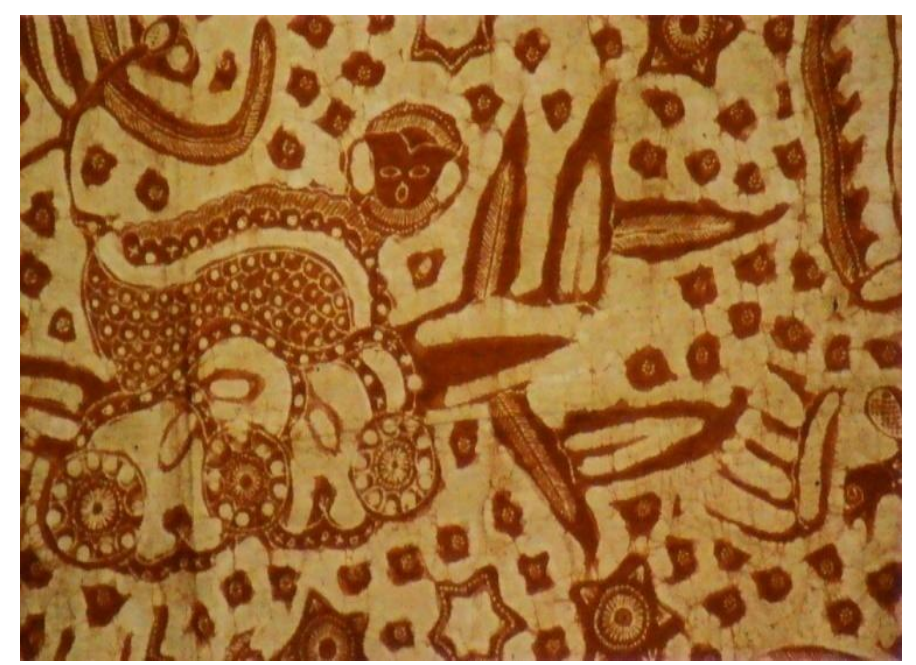

Figure 1 Another detail of a coastal batik sarong, from Lasem. The natural red dye is taken from the roots of mengkudu/noni (Morinda Cirifolia) or, in Sundanese, pace. Repeated dyeing for the desired colors causes the dye to be absorbed through the small cracks in the blocking wax. This process results in the lines or spots that wholly enrich the motif [2]. 


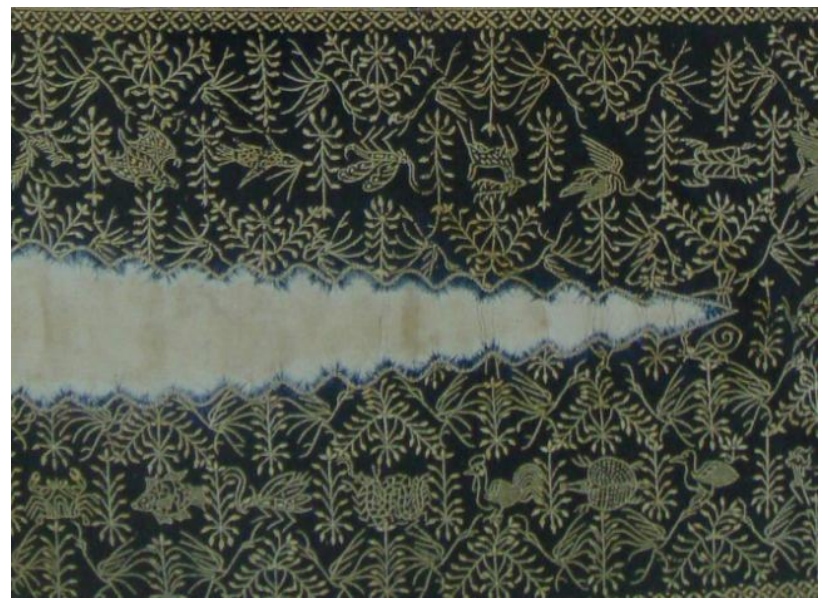

Figure 2 Royal ceremonial skirt cloth (Godot Bangun Tolak Alas-Alasan Pinarada Mas), from Surakarta, Java, Indonesia, late 19th century, cotton, natural dyes, gold leaf, stitch-resist dyeing, gold-leaf gluework [3].

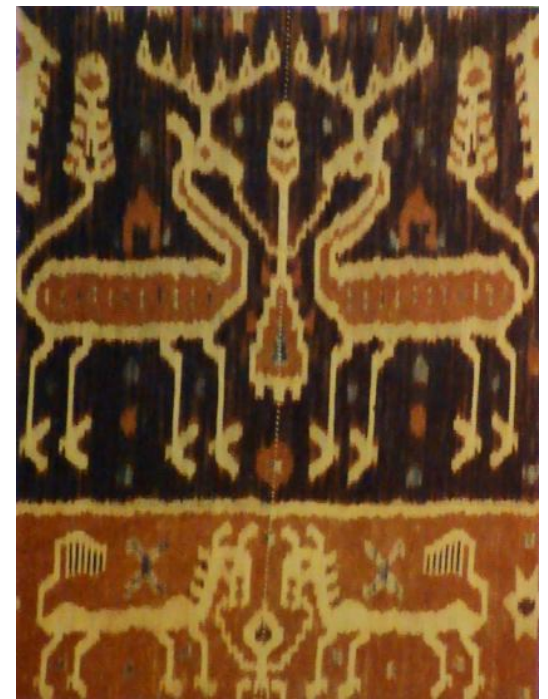

Figure 3 Hinggi Kombu (detail) from East Sumba, with the characteristic red from mengkudu roots [4].

Nevertheless, the optimism in using natural coloring matters is recently awakening. This tendency grows along with the issues of awareness of nature and the soaring popularity of back-to-nature lifestyle, which seem to counteract the issue of global warming. The awareness in using environmentally friendly products is currently increasing, causing the emergence of products labeled green design, green product, eco-labeling, eco-fashions, and several others. The 
products which are recently gathering attention from the aware consumers are the textile products made of indigenous natural fibers and using natural coloring matters. Those products are considered environmentally friendly.

\section{The Preparation of Natural Dyes}

The traditional way to obtain perfect dyes is in general by immersing material such as leave, bark or roots and seed, etc. in water. Usually they use big earthenware as container and last about five or more days, depending on the material that are immersing. After the material is decayed and dissolved, the sediment is discarded and ingredients such as variety of soils, ash or chalk, and others are then added. The kind of ingredients as well as the process of preparing the dyes sometimes differs from region to region, which in the same time determents the quality as well as the shade of color though the basic material is the same.

The shade can become the characteristic of the particular region, or even of a particular craft person. The mixing of dyes and process of dyeing are in themselves trade secrets of the craft person, even of the particular tribe.

\section{$4 \quad$ The Process of Dyeing}

Dyeing with natural dyes takes time. This is the reason why people now prefer to use synthetic dyes, since they are easier to handle and offer a greater variety of colors. In the old day, the dyeing is considered woman's work, and was even thought to be taboo for men.

Certain preconditions have to be met before the dyeing process could be started. For instance one has to fast or mutih (drinking only water and eating white rice), to rid her from negative emotions. There are also who give offerings before staring the dyeing process to avoid failure. But to day, using synthetic dyes, dyeing is done by men and the old preconditions are no longer applied.

\section{$5 \quad$ Various Kind of Natural Dyes}

Traditional natural dyes which at present are not much used anymore, are obtained from plants or trees and roots, include:

Blue: also called indigo or nila, is obtained from the tarum or tom plant (indigofera tinctoria). The branches and leaves are soaked in water for several days, and then mixed with various kind of ingredients and water is filtered, used as dyes. 
Red: this color is obtained from the mengkudu (morinda citrifolia) or from sepang (caesalpinia sapan) tree. The roots are pounded and then soaken in water mixed with other inggredients. The colors made from the sepang tree are brighter than that made from the mengkudu tree, and mixed with certain ingredients one will obtain purple and reddish brown color [5]:

1. Sogan (brown): obtained from the extract of the bark of the tinggik tree (ceriop candolleana); used to dye from light to dark brown.

2. Black: extracted from pulverized fruit of kind of black wood (diospyroebenam). It also can be obtained by mixing dark blue and dark red dyes or by re-dyeing the already dark blue colored cloth with dark red dyes. There are people who immerse the cloth in black mud.

3. Reddish brown: from the leaves of the jati tree (tectona grandis); a dull brown color is obtained from the wood of the pinang tree (areca catechu) and the wood of kayu tinggik.

4. Yellow: from the root of the kunyit or turmeric plant (curcuma domestica) and the leaves of the related plant (carthamus tinctorius), and from the leaves and bark of the mango tree (mangifera laurinia) and jack-fruit tree (artocarpus intergrifolia).

5. Green: from the leaves of the cotton plant and the bark of the mango tree. This color can also be obtained by re-dyeing of the yellow dyed cloth/yarn with blue dye.

6. Purple: from the peel of the mangos-teen fruit (garcinia mongostana). It is believed that any event or happening in one's life is inseparable with nature.

\section{$6 \quad$ Plants Producing Natural Dyes}

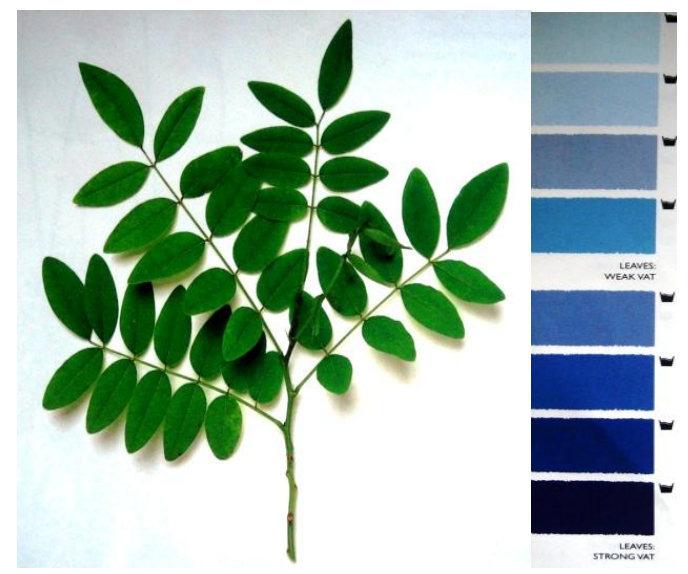

Figure 4 INDIGO/TARUM (Indigofera tinctoria) and its variation of colors [1]. 


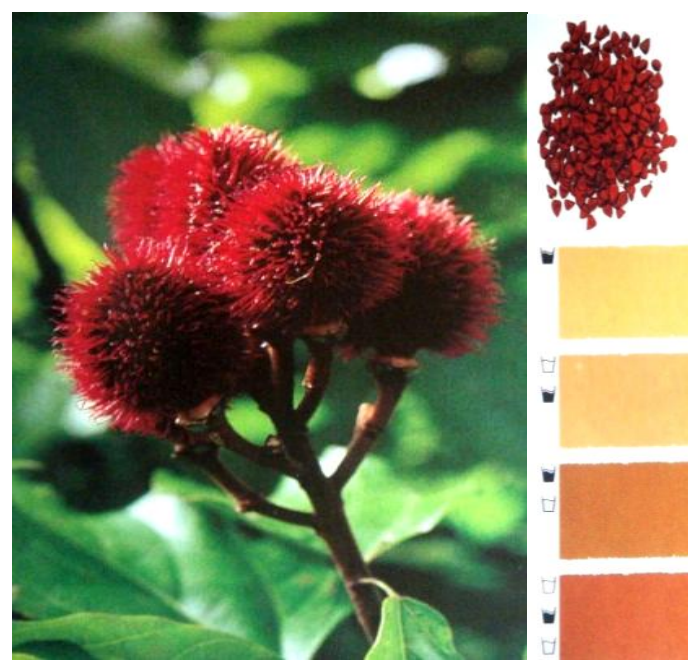

Figure 5 KESUMBA/GALINGGEM (Bixa orelana) [1] and its variation of colors.

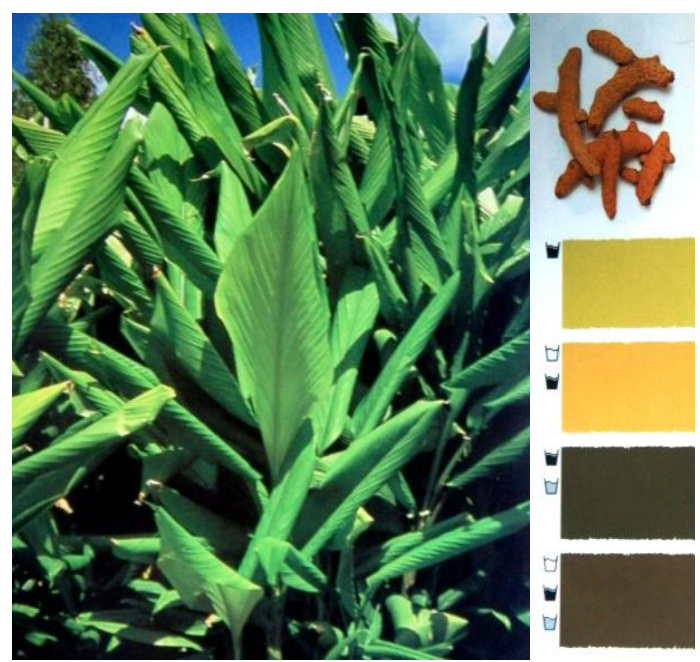

Figure 6 KUNIR (Curcuma domestica) and its variation of colors [1].

\section{$7 \quad$ Textiles Using Natural Fibers and Dyes in Modern Indonesia}

Since the invention of aniline synthetic dyes at the end of the 19th century by German scientist, the role of natural dyes has been fading. Only those who appreciate the value of traditional textiles and their accompanying cultural contents could comprehend the uniqueness of natural dyes. They are usually historians, cultural elites, collectors, and artists [4]. 
The appreciation of natural fibers and dyes leads to the formation of communities of natural dye textile enthusiasts. These communities usually emphasize on prestige and concerns toward issues of environment, environment-friendly concepts, back-to-nature lifestyles, as well as the appreciation of the values of national culture.

In the modern era, certain producers begin to find ways to produce textiles using natural dyes based on traditional process, but with a higher efficiency rate, by replacing, for instance, other traditional ingredients with newer materials, to ensure faster and more complete color absorption.

The recent usage of natural dyes in Indonesia is emphasized more on the consumers' need to find alternative products containing local values. Those products also contain historic and nostalgic values, and are, therefore, more 'human,' as well as considered more environmentally friendly. The more complicated production process compared to that of the synthetic dyes, results in higher prices and exclusivity. For this reason, textiles made of natural fibers and dyes belong to a different class, not equal to those produced using synthetic dyes, although each has its own special role. Synthetic dyes were invented due to high consumer demands which cannot be quantitatively fulfilled by natural dyes.

Based on a brief observation, there are several differences between the Indonesian traditional textiles which are related to the customs of their origins and the non-traditional textiles which also make use of natural fibers and dyes. The differences cover several aspects, namely:

1. purpose of making

2. philosophical background

3. production process

4. visuals: ornaments and colors

5. production technique

6. usage

Those aspects may be elaborated as the following:

1. Indonesian traditional textiles related to the customs of their origins. These textiles exclusively use natural fibers and dyes and they usually possess these aspects:

a. They are made to fulfill ritual or religious purposes of certain traditional beliefs (the production process is part of the ritual)

b. They contain certain philosophies, depending on their origins. 
c. Their production process involves proficient skills and is usually timeconsuming.

d. Visually, they are swarmed with ornaments, rich in colors, complicated, and detailed.

e. Their ornaments possess symbolic values

f. They are used for certain traditional rituals.

2. Non-traditional textiles using natural fibers and dyes:

a. They are made to fulfill the demands of alternative and environmentally friendly products which possess local values.

b. They are almost sterile from philosophical values, and usually bring about environmental values.

c. Their production process is arguably simple and short, with new breakthroughs toward efficiency.

d. Visually, they are relatively simple, using one or two colors for the sake of efficiency.

e. The ornaments are usually decorative and occasionally symbolic.

f. Their usage is not limited to rituals and is, therefore, more flexible.

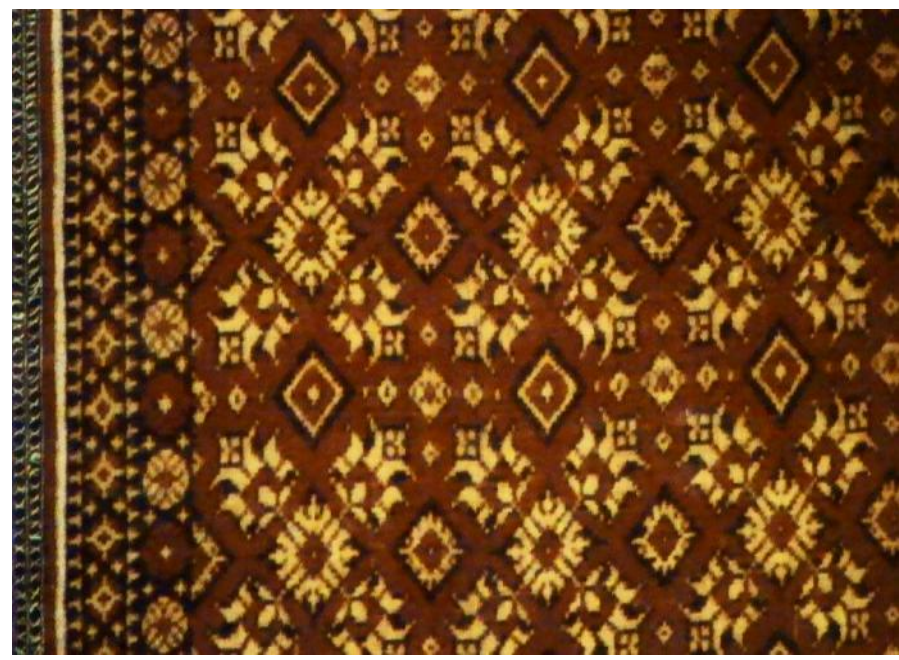

Figure 7 An example of traditional fabric using natural dyes: Geringsing Cecempaka Retang. The fabric is made of brownish red and pale yellow cotton threads. The ornaments used are double ties with floral, spiraling leave, and champaca flower patterns, interspersed by star shapes and other geometrical lines. Geringsing in the pangur gigi (teeth filing) ritual is considered having a magical power, especially to repel bad luck during the ritual [4]. 


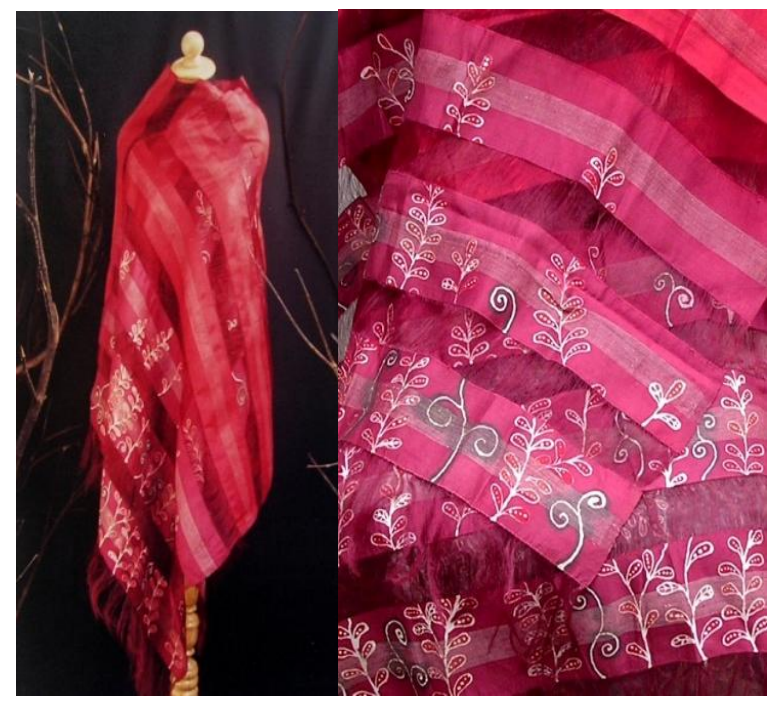

Figure 8 An example of non-traditional textile work by Mia Megasari. The materials used are pineapple fiber and sapan wood /dark red dyewood (Caesalpinia sappan L) natural dye. (Picture: Dian Widiawati).

\section{The Opportunity of Natural Dyes Revival}

The discussion of the possibilities of reusing natural dyes is currently increasing. One of the causing factors of this discussion is the regulation that prohibits the usage of certain synthetic dyes, due to their chemical ingredients which may be harmful for human beings and the environment. The prohibited dyes, for example, are those containing the diazonium salt (such as naftol, which is widely used in batik production), since the salt is a carcinogenic substance [6]. The regulation brings about a considerable impact to the production sector, especially in the sector known as textile and textile products, and to the consumers of the synthetic dyes in general. The possibility of using natural dyes as the substitute for synthetic dyes is currently undergoing research. According to recent information, the reusing of natural dyes will involve varied and complex activities. The usage of natural dyes as the substitute needs further careful research and consideration.

One of the basic problems of the present usage of natural dyes is the historical background of how natural dyes are left behind in favor of synthetic dyes. The discourses on this problem reveals various facts, especially concerning the contexts and relation to the social, economic, and production technology fields, which may be considered as a valuable input before applying the usage of natural dyes, especially for textile and textile products. Thus so, natural dyes 
may be positioned in a proportional and proper role among the heterogeneity of similar products currently demanded by consumers. The social context brings into light the shift of cultural values and its impact toward popularity, appreciation, and re-appreciation of traditional cultural products. Within the context of the existence and usage of traditional textiles, the usage of natural dyes is not merely a process of engineering the production of technology.

From the aspect of socio-economical technology, natural dyes face the greatest challenge from synthetic dyes, which will question the usefulness and the successfulness of natural dyes in the sector of textile and textile products. Other aspects in question are the availability and continuity of standard raw materials in the upstream, transitional, and downstream industrial sectors, distribution sector, and market segmentation which will affect other sectors, including the social sector.

The existence of synthetic fibers and their variations which dominate the market limits the involvement of natural dyes (since the effective application of natural dyes is on natural fibers, which have the most optimal affinity toward natural dyes). As long as there is no new breakthrough in the production technology, it will be difficult for natural dyes to regain its role in the past, as the only source of coloring matters. On the opposite, the development of research, technology, and engineering will soon anticipate the shortcomings of synthetic dyes and produce new synthetic dyes twice as advantageous.

What if the prohibition does not exist or no harmful substance is found inside synthetic dyes? Will there be any attention to revive the potential of natural dyes? Will there be an opportunity to look forward to reviving natural dyes, besides the external factors, namely the prohibition, eco-labeling, and others. Will there be a chance to revive natural dyes based on their internal potentials, without having to be controlled by external factors? If there are potentials, where do they lie and how is the best strategy to develop the potentials?

As long as there is no breakthrough in the research and engineering of natural dyes which will make it as useful and successful as synthetic dyes, it is difficult for natural dyes to have an opportunity to play a leading role in the fiber and fashion business controlled by the market, in both small and large scales, since the success is measured through the rules of the manufacturing industry of mass culture styles. The rules require submission to uniformity of quality, reduction of price according to the high quantity of minimum order, and are affected by the laws of mass production technology and engineering oriented toward the 'market-driven' view. This kind of industry is not at all wrong. It even needs more support since it is necessary and, controversy aside, is one of the important factors in the development of national economy. 
Although so, the kind of industry mentioned is not the only approach. The production process does not always have to be uniform, carefully measured, and predictable. Consumers do not always need the same and uniform products. In the fashion business, there is a great desire to be unique, to be different from others. This can be seen as an opportunity.

Being anticipative and proactive in providing an alternative solution of reviving natural dyes is therefore more important than trying to confront synthetic dyes, which is yet to produce something significant. Natural dyes and synthetic dyes need not be confronted to each other since each has its own mission and importance. Natural dyes are supposedly positioned within the great cultural heritage, where they can exist, succeed, and be promoted according to the values that they contain, as well as be acknowledged as an indigenous technology. The socio-cultural aspect of the existence of natural dyes in the long history of traditions in the archipelago holds numerous secrets of expressions of civilization and human thoughts. Nevertheless, the aspect never seems to gain much attention and natural dyes are seen as mere illustrations. The discussion of the aspect is yet to appear in various activities involving the technology of coloring matters, even though this aspect holds the greatest potential of natural dyes.

However, the potential can only be visible when we not only use the point of view of economic-engineering, but also use the point of view of arts and culture to perceive the 'economic' potential of a commodity and to offer the potential to the new markets created through cultural development in the society, where the 'secret' probably lies.

A certain strategy is required to promote natural dyes as products worth appreciating and worth having, not because of their technological advancement, but because of their social, historical, and cultural backgrounds. Vast knowledge in the field is also required besides technical skills.

For example, in the past, colors and the nature that produces them are not only raw materials but they also have symbolic meanings and represent supernatural powers which are to the survival of their producing communities. The appearance of colors in various products, especially fabrics, becomes an important part of traditional rituals. Another distinctive quality of natural dyes is their 'weakness,' their unpredictability and their lack of standardized quality of color expression. The qualities of water, mineral contents, and climate have been known as the factors that cause the differences in similar colors produced in several regions. Amidst the mass culture that exalts uniformity, the 'weakness' of natural dyes might as well become their selling point. There are varying types of uniqueness, both related directly and indirectly to natural dyes, 
which can be explored further to support the promotion of natural dyes. The uniqueness may cover the origin of a particular dye, from the cultivation of the dye-producing plant to the manual blending of ingredients which causes also a distinct aroma, the usage of the dye in rituals, ornaments, traditional fashion, folk tales, and many other purposes. Thus, it is important to realize that the knowledge of the uniqueness is significant and is the selling point of natural dyes, which may not be found in any other places.

The relevance of availability of raw materials and processing skills to the determination of product types and variations also deserves a special attention. The ability of nature to provide natural dyes is not as sustainable as it used to be and is different from one region to another. This will affect the availability of products using natural dyes, both quantitatively and qualitatively. A new strategy is then required in the sector of production among natural dyes production centers. In this case, the role of a supporting element of natural dyes becomes important: natural fibers (which may not be as extensive as natural dyes, but are also facing the same existential problems). The diversity of tropical plants in Indonesia is a force to be reckoned with. It is able to complete and widen the range of variation of product using natural dyes. Similar to natural dyes, natural fibers physically have the same origins and interesting historical and cultural backgrounds. Natural fibers are the most important partner of natural dyes, ever since their first inception. It is not exaggerating to say that natural fibers empower natural dyes. The recent development of natural fibers focuses on the experiments using various alternative natural fibers, such as abaca (musa textilis), agel (corypha gebanga), klowong cotton, eceng gondok/ water hyacinth (Eichornia crassipes), banana, and corn husk. There are also other materials that support natural dyes, such as animal skin, various types of wood and bark, bamboo, and rattan.

It is important to know the segmentation or the group of the market/society that demands natural dye products. This segment appears due to the recent development of technology and arts, which results in individual appeal, opinion, and perception. Pluralism in the postmodern society is becoming reality. If the society in the twentieth century craves for products of mass fabrication which (by force) cause the necessity for synthetic substances, then today and in the future, people look for limited products with wide ranges of diversification, which bring about the search for and re-appreciation of cultural roots and attention toward natural and environmental reservation. The emergence of the terms 'ethnic design', 'back to nature', 'recycled products', 'environmentfriendly', and 'biodegradable' shows the tendency to support the reservation which, in turn, points to the potential of natural dyes and the opportunity to develop them to answer the challenge according to the natural dyes' inherent 
values. One of potential segments for natural dyes is of course the tourism market, projected to become the reliable industry of the future.

\section{Preliminary Conclusion}

It is clear that the revival of natural dyes in the context of cultural approach is not a sectoral job or a job relying only on one type of skill. Besides the carefulness in promoting and publicizing, marketing and management, the producers must also have skills in plant cultivation, inventorying of craft centers and proficient craftsmen who are ready to inherit their skills to new craftsmen. The involvement of expertise in craft product design where natural dyes are a part of is also essential in positioning and marketing strategies. In brief, although the revival of natural dyes relies on cultural approaches, a professionally coordinated network among arts, socio-cultural elements, engineering, and economy is necessary. If this is achieved, the revival of natural dyes will have its full opportunity.

\section{Acknowledgement}

Gratefully acknowledge Dr. Biranul Anas Zaman, Faculty of Fine Art And Design, ITB, Drs. Hendri Suprapto, for providing the data and Information.

\section{References}

[1] Dean, Jenny. 1999. Wild Colour, Octopus Publishing Group Ltd. London.United Kingdom.

[2] Anas, Biranul, et al. 1995. Batik, Indonesia Indah, 8, Yayasan Harapan Kita/BP3 TMII, Jakarta, Indonesia.

[3] Maxwel, Robyn. 2003. Sari To Sarong, Five Hundred Years Of Indian Art Indonesia Textile Exchange, Nation Gallery of Australia.

[4] Anas, Biranul, et al. 1995. Tenunan Indonesia, Indonesia Indah, 3, Yayasan Harapan Kita/BP3 TMII, Jakarta, Indonesia.

[5] Djoemena, Nian S. 2000. Lurik, Garis-Garis Bertuah, The Magic Stripes, Djambatan,Jakarta, Indonesia.

[6] Suprapto, Hendri. 2000. Penggunaan Zat Pewarna Alami untuk Batik, Balai Besar Penelitian dan Pengembangan Industri Kerajinan dan Batik, Yogyakarta, Indonesia. 